\title{
Acute Flaccid Quadriparesis in a Recovering COVID-19 Patient: A Clinical Dilemma
}

\author{
Pranshuta Sabharwal $^{1} \odot$, Sangeeta Chakraborty ${ }^{\circledR}{ }^{\circ}$, Niraj Tyagi $^{3} \odot$ Amber Kumar $^{4} \odot$
}

Keywords: COVID-19, Guillain-Barré syndrome, Quadriparesis.

Indian Journal of Critical Care Medicine (2021): 10.5005/jp-journals-10071-23728

A 39-year-old woman developed progressive breathing difficulty on July 7 which on evaluation at a private hospital was tested positive for COVID-19 RT PCR. After one day of stay, the patient came to our hospital on a non-rebreathing mask. The increasing oxygen requirement led to intubation and mechanical ventilation on the second day of admission. Patient was managed with intravenous cefuroxime sulbactam $1.5 \mathrm{gm} \mathrm{BD}$, methylprednisone $60 \mathrm{mg}$ BD for five days which was tapered over the next 4 days, inj Remdesivir $200 \mathrm{mg}$ for the first day followed by $100 \mathrm{mg}$ OD next 4 days, and thromboprophylaxis in the form of dalteparin 5000 subcutaneously $\mathrm{BD}$. On the very next day after intubation patient was prone in view of the low $\mathrm{PaO}_{2} / \mathrm{FiO}_{2}$ ratio. After three proning sessions patient was finally extubated on July 19 . On the third day post extubation, the patient was on room air and ward shifting was planned when the patient complaint of tingling sensation along with weakness in the lower limbs which progressed and involved the upper limb the next day. The neurologic examination revealed severe (medical Research council grade 2/5) distal symmetrical upper and lower limb weakness, loss of deep tendon reflexes, preserved pinprick, and light touch sensation. On the fifth day of post-extubation, an MRI brain and spine were done to rule out any nerve compression, which was normal. Also, a nerve conduction study was done. Neurophysiologic findings were suggestive of acute motor-sensory axonal neuropathy suggesting a clinical diagnosis of Guillain-Barré syndrome (GBS) (Table 1), ${ }^{1}$ although the possibility of peripheral neuropathy secondary to any drug or critical illness itself could not be ruled out. However, the consent for lumbar puncture was not given by the patient hence could not be done initially. Clinically, the patient maintained oxygenation on nasal prongs $4-6 \mathrm{~L} / \mathrm{min}$ flow and the oxygen requirement did not increase further. Based on clinical suspicion and NCV finding patient was started on intravenous immunoglobulin infusion $2 \mathrm{gm} / \mathrm{kg}$ for 5 days. Patient's weakness started improving gradually and by the third day of IVIg therapy, the patient came on room air with some residual paresis in lower limbs. After three days of IVIg, therapy patient agreed to undergo a lumbar puncture. In pursuit of establishing the diagnosis, a lumbar puncture and CSF study was done, which came out to be negative for albuminocytological dissociation. IVIg was discontinued after three days because of lack of evidence. Patient continued to improve gradually and was discharged after 22 days of hospital stay.

Neuromuscular weakness amounting to flaccid quadriparesis in recovering patients in ICU is fairly common. Some common causes possible for ICU-acquired weakness (ICUAW) in this patient could be (1) critical illness neuropathy (CIN), (2) drug-induced peripheral

\author{
${ }^{1-4}$ Department of Critical Care Medicine, Sir Ganga Ram Hospital, New \\ Delhi, India \\ Corresponding Author: Sangeeta Chakraborty, Department of Critical \\ Care Medicine, Sir Ganga Ram Hospital, New Delhi, India, Phone: +91 \\ 9830356827, e-mail: brightsky@rediffmail.com \\ How to cite this article: Sabharwal P, Chakraborty S, Tyagi N, Kumar A. \\ Acute Flaccid Quadriparesis in a Recovering COVID-19 Patient: A \\ Clinical Dilemma. Indian J Crit Care Med 2021;25(2):238-239. \\ Source of support: Nil \\ Conflict of interest: None
}

neuropathy, (3) steroid-induced myopathy, (4) neuromuscular blockade (NMB) related muscle weakness, (5) prone position leading to spinal nerve root compression, (6) dyselectrolytemia, and (7) GBS. ${ }^{2}$ After ruling out the possibility of causes (3)-(5) by MRI and NCV and ruling out dyselectrolytemia and any drug causing peripheral neuropathy clinical dilemma persisted between causes (1) and (7). Cases of GBS have been reported in patients infected with SARS-CoV-2 after 10-15 days of symptom onset., Typically, our patient presented with this weakness, 14 days after the symptom onset with a characteristic distal symmetrical pattern and a characteristic NCV which leaned our diagnosis towards GBS. Improvement after initiation of IVIg substantiated the clinical diagnosis further. CIN is also fairly common in ICU after the first two weeks of turbulent clinical course. Considering the fact that CIN commonly manifests as weaning failure, the clinical manifestation here was unclear, ${ }^{5}$ but having an axonal neuropathy with absent albuminocytological dissociation leaves us with a conclusion of probable diagnosis of CIN masquerading as GBS.

\section{ORCID}

Pranshuta Sabharwal @ https://0000-0003-3914-5867

Sangeeta Chakraborty (ㄴ) https://orcid.org/0000-0003-1331-1572

Niraj Tyagi (i) https://0000-0001-5862-9731

Amber Kumar (1) https://0000-0003-3411-5917

\section{References}

1. Hadden RD, Cornblath DR, Hughes RA, Zielasek J, Hartung HP, Toyka KV, et al. Electrophysiological classification of Guillain-Barré syndrome: clinical associations and outcome. Plasma Exchange/ Sandoglobulin Guillain-Barré Syndrome Trial Group. Ann Neurol 1998;44(5):780-788. DOI: 10.1002/ana.410440512. 
Table 1: Nerve conduction study results

\begin{tabular}{|c|c|c|c|c|}
\hline Nerve conduction & $\begin{array}{l}\text { Distal } \\
\text { latency } \\
\text { (ms) }\end{array}$ & $\begin{array}{l}\text { Amplitude } \\
(m V)\end{array}$ & $\begin{array}{l}\text { Conduction } \\
\text { velocity } \\
\left(\mathrm{ms}^{-1}\right)\end{array}$ & $\begin{array}{l}\text { Area } \\
m V \times m s\end{array}$ \\
\hline \multicolumn{5}{|c|}{ Motor } \\
\hline \multicolumn{5}{|l|}{ Right median } \\
\hline Wrist & 2.5 & 4.4 & & 17.3 \\
\hline Elbow & 6.5 & 4.2 & 55.8 & 15 \\
\hline Arm & 7.7 & 3.7 & 49.9 & 10.5 \\
\hline \multicolumn{5}{|l|}{ R ulnar } \\
\hline Wrist & 3.1 & 4.0 & & 14.6 \\
\hline Elbow & 6.4 & 3.7 & 64.2 & 14.0 \\
\hline Arm & 7.6 & 3.6 & 60.6 & 13.2 \\
\hline \multicolumn{5}{|l|}{ R peroneal } \\
\hline Sole of the foot & 2.2 & 1.3 & & 8.7 \\
\hline Head of the fibula & 11.8 & 1.4 & & 9.3 \\
\hline Popliteal fossa & 12.8 & 1.3 & & 7.5 \\
\hline \multicolumn{5}{|l|}{ L peroneal } \\
\hline Sole of the foot & 6.6 & 0.3 & & 1.5 \\
\hline Head of the fibula & 12.5 & 0.3 & 46.4 & 1.7 \\
\hline Popliteal fossa & 13.9 & 0.4 & 50.2 & 2.6 \\
\hline \multicolumn{5}{|l|}{ R tibial } \\
\hline Medial malleolus & 6 & 3.1 & & 8.9 \\
\hline Popliteal fossa & 12.7 & 3.3 & 57.2 & 14.5 \\
\hline \multicolumn{5}{|l|}{ L tibial } \\
\hline Medial malleolus & 8.4 & 4.2 & & 19.9 \\
\hline Popliteal fossa & 17 & 4.3 & 44.3 & 23.1 \\
\hline \multicolumn{5}{|c|}{ Sensory } \\
\hline \multicolumn{5}{|l|}{ R median } \\
\hline Digit & 2.1 & 15.4 & 56.1 & 10.2 \\
\hline Midpalm & 1.4 & 49.1 & 44.1 & 45.7 \\
\hline \multicolumn{5}{|l|}{ R ulnar } \\
\hline Digit & 1.9 & 19.9 & & 26.8 \\
\hline Midpalm & 1.0 & 3.2 & & 1.6 \\
\hline
\end{tabular}

$\mathrm{mV}$, millivolt; $\mathrm{ms}$, milliseconds
2. Lipshutz AKM, Gropper MA. Acquired neuromuscular weakness and early mobilization in the intensive care unit. Anesthesiology 2013;118(1):202-215. DOI: 10.1097/ALN.0b013e31826be693.

3. Toscano G, Palmerini F, Ravaglia S, Ruiz L, Invernizzi P, Cuzzoni MG, et al. Guillain-Barré syndrome associated with SARS-CoV-2. N Engl J Med 2020;382(26):2574-2576. DOI:10.1056/NEJMc2009191.

4. Arnaud S, Budowski C, Ng Wing Tin S, Degos B. Post SARS-CoV-2 Guillain-Barré syndrome. Clin Neurophysiol 2020;131(7):1652-1654. DOI: 10.1016/j.clinph.2020.05.003.

5. Zhou C, Wu L, Ni F, Ji W, Wu J, Zhang H. Critical illness polyneuropathy and myopathy: a systematic review. Neural Regen Res 2014;9(1):101110. DOI: 10.4103/1673-5374.125337. 